Louisiana State University

LSU Digital Commons

Faculty Publications

Department of Biological Sciences

$11-1-2016$

\title{
The negative effects of pathogen-infected prey on predators: a meta-analysis
}

Andrew J. Flick

Louisiana State University

Miguel A. Acevedo

University of Puerto Rico

Bret D. Elderd

Louisiana State University

Follow this and additional works at: https://digitalcommons.Isu.edu/biosci_pubs

\section{Recommended Citation}

Flick, A., Acevedo, M., \& Elderd, B. (2016). The negative effects of pathogen-infected prey on predators: a meta-analysis. Oikos, 125 (11), 1554-1560. https://doi.org/10.1111/oik.03458

This Article is brought to you for free and open access by the Department of Biological Sciences at LSU Digital Commons. It has been accepted for inclusion in Faculty Publications by an authorized administrator of LSU Digital Commons. For more information, please contact ir@lsu.edu. 


\title{
The negative effects of pathogen-infected prey on predators: a meta-analysis
}

\author{
Andrew J. Flick, Miguel A. Acevedo and Bret D. Elderd \\ A.J. Flick (aflick1@lsu.edu) and B. D. Elderd, Dept of Biological Sciences, Louisiana State University, Baton Rouge, LA 70803, USA. - M. A. \\ Acevedo, Dept of Biology, Univ. of Puerto Rico, San Juan, PR, USA.
}

\begin{abstract}
Intra-guild predation (IGP) - where a top predator $\left(\mathrm{IG}_{\text {Pred }}\right)$ consumes both a basal resource and a competitor for that resource $\left(\mathrm{IG}_{\text {Prey }}\right)$ - has become a fundamental part of understanding species interactions and community dynamics. IGP communities composed of intraguild predators and prey have been well studied; however, we know less about IGP communities composed of predators, pathogens, and resources. Resource quality plays an important role in community dynamics and may influence IGP dynamics as well. We conducted a meta-analysis on predator-pathogen-resource communities to determine whether resource quality mediated by the pathogen affected predator life-history traits and if these effects met the theoretical constraints of IGP communities. To do this, we summarized results from studies that investigated the use of predators and pathogens to control insect pests. In these systems, the predators are the $\mathrm{IG}_{\text {Pred }}$ and pathogens are the $\mathrm{IG}_{\text {Prey }}$. We found that consumer longevity, fecundity, and survival decreased by $26 \%, 31 \%$ and $13 \%$ respectively, when predators consumed pathogen-infected prey, making the infected prey a low quality resource. Predators also significantly preferred healthy prey over infected prey. When we divided consumers by enemy type, strict predators (e.g. wolf spiders) had no preference while parasitoids preferred healthy prey. Our results suggest that communities containing parasitoids and pathogens may rarely exhibit intraguild predation; whereas, communities composed of strict predators and pathogens are more likely dominated by IGP dynamics. In these latter communities, the consumption of low and high quality resources suggests that IGP communities composed of strict predators, pathogens and prey should naturally persist, supporting IGP theory.
\end{abstract}

We investigated how consuming pathogen-infected prey influence important life-history parameters of insect predators. Pathogens are used in a variety of biocontrol programs, especially to control crop pests. We found $\frac{n}{5}$ that true predators (i.e. wolf spiders) have no preference for healthy or infected prey and have reduced fecundity, survival and longevity consuming infected prey. However, parasitoids avoided infected prey when possible. In है biocontrol programs with multiple control agents, parasitoids and pathogens would do a better job controlling pests as predators would reduce the amount of pathogen available and have reduced fitness from consuming infected prey. However, theory suggests that true predators, prey and pathogens may coexist long term.

Top-down interactions play a vital role controlling population dynamics at lower trophic levels (Paine 1980, Power et al. 1985, Kohler and Hoiland 2001, Schmitz and Suttle 2001). Typically, these interactions consist of a predator consuming its prey or a pathogen consuming its host. Historically, studies that allowed for multiple predators in a community assumed they acted as competitors (Griffiths and Holling 1969, Bazykin et al. 1981, Creel and Creel 1996); however, predators and pathogens may affect community dynamics through intraguild predation (IGP). IGP interactions between predators have been well studied empirically (Rosenheim et al. 1993, Browne and Rasmussen 2013) and synthesized through meta-analyses (Vance-Chalcraft et al. 2007, Mooney et al. 2010). These studies suggest that the effects of the predator on the resource vary across ecosystems and the species of the predator. While Thomas et al. (2006) suggested that parasitoids and pathogens interact through IGP, few studies have set out to directly test this hypothesis. The importance of parasites for understanding community ecology and structure has recently been recognized; however, it is still a major gap in the literature (Johnson et al. 2010, Thieltges et al. 2013, Lafferty et al. 2008). Macro-parasites have received some attention (Rohr et al. 2015), though micro-parasites or pathogens have not been well considered.

Previous theoretical work on within generation dynamics, shows that predators under most circumstances should consume parasitized prey (Lafferty 1992). However, Lafferty (1992) only considered parasites that are trophically-transmitted (i.e. when the infected prey represent a secondary host of the parasite). Yet, a large number of parasites, both macro- and micro-, are consumed concomitantly with the 
prey and the parasites are not transmitted to the predator (Johnson et al. 2010). Additionally, Lafferty (1992) assumed that parasites do not alter the energetic value of the prey. This may not always hold true since parasites may affect the energy gained from consuming infected prey compared to non-infected prey (Thieltges et al. 2013). Changes in the energetic value of the prey, in turn, may affect the predator's foraging behavior as well as important life-history metrics (e.g. fecundity and survival).

Theory predicts that predator choice and behavior, along with prey quality (e.g. pathogen-infected or healthy), are important in determining IGP community structure (Holt and Polis 1997, Borer et al. 2007, Mooney et al. 2010, Sieber and Hilker 2011). Empirical evidence examining the impacts of predator choice and host quality on the interactions between predators and pathogens is currently lacking. However, there are a considerable number of studies showing the short-term impacts of predator choice and host quality on the intraguild predator fitness and associated lifehistory traits (e.g. predator life-span) in agricultural systems. By examining how predator behavior and life-history traits may change due to interactions with pathogens specific to the prey, we can gain greater insight into IGP community dynamics.

In general, IGP communities consist of three main players: an intraguild predator $\left(\mathrm{IG}_{\text {Pred }}\right)$, an intraguild prey $\left(\mathrm{IG}_{\text {Prey }}\right)$, and a basal resource (Fig. 1). In agricultural systems specifically, many biocontrol programs use a combination of predators and pathogens, creating predator-pathogenresource IGP communities (Poland et al. 2007). The experiments investigating these biocontrol programs provide information on how a single pathogen influences life-history traits of a single, non-target predator. These experiments isolate the IGP interaction without having to separate the various components of a community into simplified community modules (Holt and Polis 1997). Thus, a metaanalysis of these single IGP systems will allow us to make generalizations about how resource quality influences IGP interactions.

In this study, we used a meta-analytical approach to synthesize empirical work on how prey quality influences

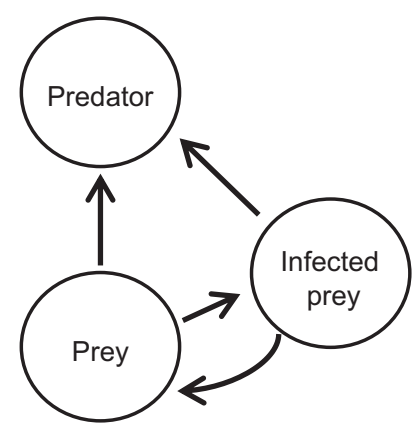

Figure 1. A diagram of interacting enemies described by intraguild predation (IGP) including a predator $\left(\mathrm{IG}_{\text {Pred }}\right)$, a pathogen $\left(\mathrm{IG}_{\text {Prey }}\right)$, and a prey resource. Arrows represent the conversion of biomass. Here, the $\mathrm{IG}_{\text {Prey }}$ is represented by an infected prey. The lower black curved arrow represents infected prey that clear the pathogen and become healthy prey. The $\mathrm{IG}_{\text {Pred }}$ can consume either infected prey or healthy prey. The pathogen can only infect healthy prey. Adapted from Borer et al. 2007. predator behavioral and life-history traits in pathogendriven IGP communities consisting of predators, pathogens and prey. Since most field experiments do not run long enough to investigate long-term population dynamics, we were limited to life-history responses within a generation. We further focused our efforts on crop pest insects as resources, infected pest insects as $\mathrm{IG}_{\text {Prey }}$, and their predators as $I_{\text {Pred }}$ (Fig. 1), given the plethora of studies available and the degree to which these studies are able to isolate IGP interactions (Supplementary material Appendix 1 Table A1). In agricultural ecosystems, a great deal of research is focused on economically costly pests and controlling them (King and Saunders 1984, Moscardi 1999, Williams et al. 2013). While our study contains four orders of insect pests, many of these pests are contained within Lepidoptera whose members are frequently preyed upon by predators and pathogens alike (Clark et al. 1994, Moscardi 1999, Liu et al. 2014). We predict that infected resources would reduce longevity, fecundity, and survival of the $\mathrm{IG}_{\text {Pred }}$. We also predicted that predators would prefer healthy prey to infected prey across predator and pathogen types; as infected prey represent low quality resources. Our results show that lowered resource quality reduces life-history metrics such as lifespan and fecundity of the $\mathrm{IG}_{\text {Pred }}$, which can have important consequences for disease dynamics and IGP interactions.

\section{Material and methods}

\section{Literature search}

We searched the ISI Web of Knowledge database (ending November 2015) for the following Keywords: "virus insect predator", "fungus insect predator", "virus insect parasitoid" and "fungus insect parasitoid" (see Supplementary material Appendix 1 Table A4 for a list of studies used). Bacterial studies were not included for two reasons, 1) the majority focus on crops containing Bacillus thuringiensis (Bt) in their genome and thus do not represent IGP communities and 2) the majority of non-Bt studies focus on bacterial pathogens that are in some way symbiotic with their hosts (e.g. studies on the effects of Wolbachia) (Xie et al. 2014, Furihata et al. 2015). We restricted our analysis to studies that included a predator or parasitoid in the presence of both an inherently lethal pathogen-infected (treatment) and healthy prey (control). We excluded pathogens that do not regularly kill their hosts. Using these data we were able to compare the effects of consuming healthy prey versus infected prey on predator and parasitoid life-history parameters. We also included cross-citations from the studies chosen that included a consumer exposed to pathogen-infected prey.

To conduct the meta-analysis, we included studies $(\mathrm{N}=50)$ that investigated arthropod predation of crop pests that reported mean, standard errors and sample sizes. We combined all consumer and pathogen types within each life-history trait. Then we categorized the studies by pathogen type (virus or fungus) and finally consumer type (strict predator or parasitoid). Using each of the above categories (Supplementary material Appendix 1 Table A2), we analyzed whether there were differences in each of the traits considered. 
In our systematic literature review, we searched for studies that compared the influence of infected and healthy insect crop pests on non-target consumer life-history parameters (i.e. longevity, development, fecundity and survival) that influence realized fitness (Roitberg et al. 2001). We also examined predator preference when presented with healthy and infected prey. For each study, we compared control to treatment groups. Control groups of $\mathrm{IG}_{\text {Pred }}$ were exposed to healthy prey while the treatment groups were exposed to pathogen-infected prey. Each life-history parameter of the $\mathrm{IG}_{\text {Pred }}$ was defined a priori as follows. We defined the development time as the mean time from egg to adult or mean time from the nymph to the adult stage. Longevity was quantified as mean life-span from egg or nymphal stage to death. Fecundity was the mean number of eggs produced. To quantify survival, we extracted the mean number of consumers surviving after two weeks. Finally, we defined the $\mathrm{IG}_{\text {Pred }}$ choice as the mean number of infected prey chosen compared to the mean number of healthy prey chosen. In addition to these means, we also collected standard deviations and sample sizes. Many studies focused on one of the above traits, however, a few studies focused on two or more. If each life-history trait was tested independently, than they were included in our metaanalysis; if they were not independent we randomly chose only one life-history trait from a single experiment.

\section{Data analysis}

To standardize data reported in different scales or magnitudes, we calculated Hedges' $d$ weighted average metrics using means, standard deviations, and samples sizes from each study (Rosenberg et al. 2000). Hedges' $d$ incorporates overestimate-bias, working well for small sample sizes in meta-analyses $(\mathrm{N}<5)$. Mean effect sizes were considered small in the range from $0.2-0.4$; moderate effects ranged from 0.4-0.7; strong effects ranged from 0.7-1.0 (Cohen 1992, Gaskin and Happell 2013). Any results with a mean effect size greater than 1.0 were considered very strong (Cohen 1992, Gaskin and Happell 2013).

We calculated Hedges' $d$ for each study, $i$, as:

$d_{i}=\frac{\bar{X}_{i}^{E}-\bar{X}_{i}^{C}}{S} J_{i}$

where $\bar{X}_{i}^{E}$ is the mean of the treatment and $\bar{X}_{i}^{C}$ is the mean of the control group. $S$ is the pooled standard deviation of the control and experimental groups for each study within a treatment. $J_{i}$ incorporates overestimate-bias by standardizing for small sample sizes such that:

$J_{i}=1-\frac{3}{4\left(N_{i}^{C}+N_{i}^{E}-2\right)-1}$

where $N_{i}^{C}$ is the number of replicates in the control and $N_{i}^{E}$ is the number of replicates in the experimental treatment for study $i$ (Gurevitch and Hedges 1993). The variance in Hedges' $d_{i}$ is defined as:

$v_{d_{i}}=\frac{N_{i}^{C}+N_{i}^{E}}{N_{i}^{C} N_{i}^{E}}+\frac{d_{i}^{2}}{2\left(N_{i}^{C}+N_{i}^{E}\right)}$

We used Hedges' $\mathrm{d}_{i}$ values and variances to calculate the overall mean effect size, $\overline{\bar{E}}$ :
$\overline{\bar{E}}=\frac{\sum_{i=1}^{M} w_{i} d_{i}}{\sum_{i=1}^{M} w_{i}}$

where $w_{i}$ is $1 / \mathrm{v}_{d_{i}}$ and $M$ is the total number of studies. This value describes the direction (i.e. positive or negative) and the strength of the effect. The mean effect size is expressed as the number of standard deviations from the experimental treatment to the control. We considered treatments significant when their 95\% confidence intervals did not overlap zero and the absolute value of the mean effect size was greater than 0.2 (Rosenberg et al. 2000).

All analyses were conducted using MetaWin 2.1 (Rosenberg et al. 2000). If the confidence interval did not overlap zero, we used Rosenthal's value $\left(N_{R}\right)$ to determine if results were robust. This measure calculates the number of insignificant studies with mean effect size of zero needed to render our results insignificant at the 0.05 level (Rosenberg et al. 2000). We calculated Rosenthal's value as:

$N_{R}=\frac{\left(\sum_{i=1}^{N} Z\left(p_{i}\right)\right)^{2}}{Z_{\alpha}^{2}}-N$

where $Z\left(p_{i}\right)$ is defined as the individual $Z$ score for each Hedges' $d_{i}$ and $Z_{a}$ is the associated one-tail $Z$ score with $\alpha=0.05$ (Rosenberg et al. 2000). We consider Rosenthal's number to be robust if $N_{R}>5 M+10$ (Stiling and Cornelissen 2005). That is, we would still have significant results if more than five times the number of published studies were unpublished due to insignificant results.

While Hedges' $d$ incorporates a standard overestimatebias for small sample sizes, we also used trim and fill analyses which can effectively evaluate publication bias in meta-analyses (Duval and Tweedie 2000). Using this method allowed us to assess the number of missing studies due to publication bias against null results (Supplementary material Appendix 1 Table A1).

\section{Data deposition}

Data available from the Dryad Digital Repository: < http:// dx.doi.org/10.5061/dryad.9ht4g > (Flick et al. 2016).

\section{Results}

Resource quality had a significant effect on the fitness of the consumer. Pathogen infection reduced consumer longevity by $26 \%$, fecundity by $31 \%$, and survival by $13 \%$ (Fig. 2, gray triangles). When given a choice between healthy and infected prey, consumers chose pathogeninfected prey $28 \%$ less often (Fig. 2, gray triangles). Development time was not significantly longer in consumers exposed to infected prey with the $95 \%$ confidence intervals overlapping zero (Fig. 2, gray triangles). Overall, the $\mathrm{IG}_{\text {Pred }}$ decreased in survival, longevity, and produced fewer offspring when they consumed pathogen-infected prey (Fig. 2, gray triangles). 


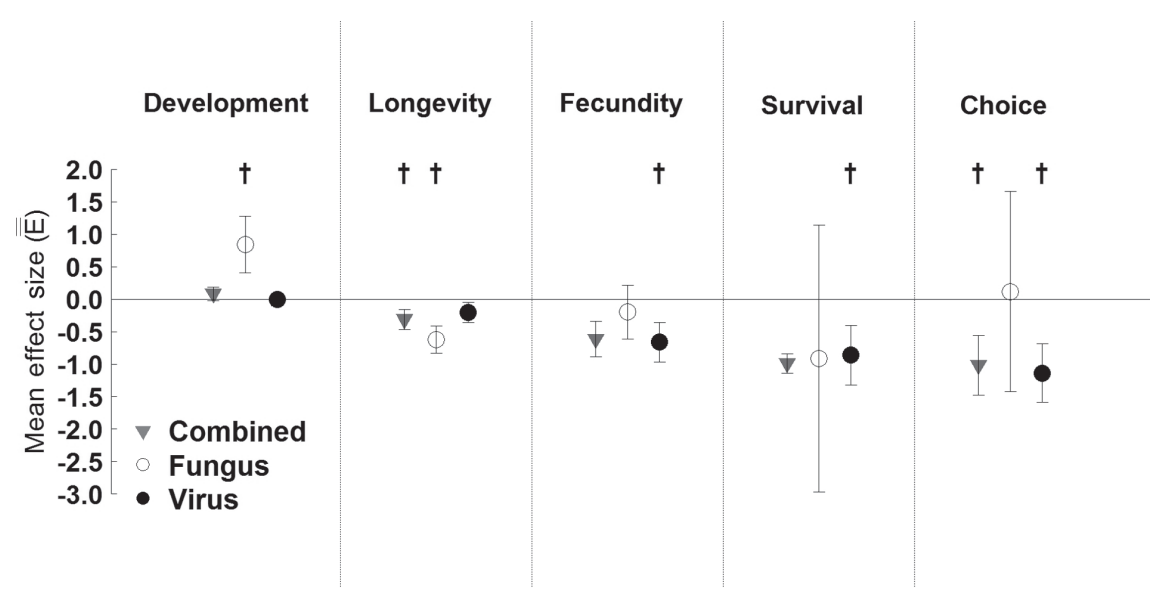

Figure 2. The effect of pathogen type on life history of the $\mathrm{IG}_{\text {Pred }}$. Mean effect sizes and $95 \%$ confidence bars for the influence of virusinfected prey (black points) and fungus-infected prey (open points) compared to healthy prey on consumer life history traits. Combined fungus and virus results are shown in gray triangles. Cross symbols above the individual points represent robust results based on Rosenthal's fail safe number $\left(N_{R}\right) . N_{R}$ is the hypothetical number of unpublished studies with null results necessary to create a non-significant result. Specific Rosenthal's values can be found in Supplementary material Appendix 1 Table A3.

When analyzing the data by pathogen type, fungusinfected prey caused a $5 \%$ increase in developmental time and a $22 \%$ reduction in longevity of the $\mathrm{IG}_{\text {Pred }}$ (Fig. 2, open points). Fungus-infected prey did not influence fecundity, survival, or choice. Prey infected with viruses caused a $29 \%$ decrease in longevity, a $32 \%$ decrease in fecundity, and a $30 \%$ reduction in survival of the $\mathrm{IG}_{\text {Pred }}$ (Fig. 2, black points). The $\mathrm{IG}_{\text {Pred }}$ chose healthy prey $29 \%$ more often than virus-infected prey (Fig. 2, black points). When examining the effects on different types of intraguild predators, virus-infected prey did not affect development of predators or parasitoids (Supplementary material Table A2). Clearly, virus-infected prey were driving the combined effect seen in Fig. 2 with respect to development and fecundity. However, virus- and fungus-infected prey both lowered consumer fitness, albeit in different ways.
Differences in various life-history metrics also depended upon whether the $\mathrm{IG}_{\text {Pred }}$ was a strict predator or a parasitoid. Parasitoids had a $22 \%$ decrease in longevity and a $32 \%$ decrease in fecundity when parasitizing pathogen-infected prey compared to healthy prey (Fig. 3, black points). Parasitoids also chose healthy prey $31 \%$ more often compared to prey infected with pathogens. Pathogen-infected prey did not influence parasitoid development or survival. For strict predators, pathogen-infected prey caused a $33 \%$ reduction in longevity, a $38 \%$ reduction in fecundity, and a $45 \%$ decrease in survival (Fig. 3, open points). However, there was no influence of pathogen-infected prey on predator development or choice. The largest overall effects were on strict predator fitness in general and parasitoid choice.

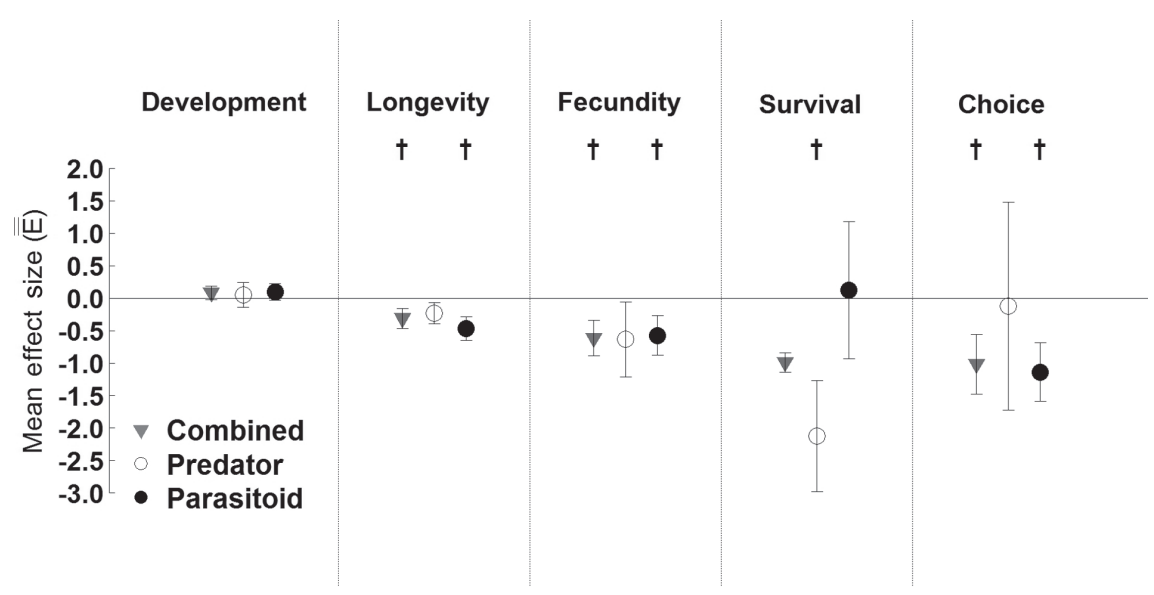

Figure 3.The effect of the $\mathrm{IG}_{\text {Prey }}$ on life history traits of predators and parasitoids. Predators and parasitoids responded differently when comparing survival and choice of infected prey to healthy prey. Mean effect sizes and $95 \%$ CIs of life history parameters of predators (open points) or parasitoids (black points) consuming infected prey compared to healthy prey. Combined predator type results are shown in gray triangles. Note, the gray triangles are the same as those in Fig. 2 and are show for comparison. Cross symbols above the individual points represent robust results based on Rosenthal's fail safe number $\left(N_{R}\right) . N_{R}$ is the hypothetical number of unpublished studies with null results necessary to create a non-significant result. Specific Rosenthal's values can be found in Supplementary material Appendix 1 Table A3. 


\section{Discussion}

Infected prey clearly represent a poor resource regardless of infection type (Fig. 2), and predators respond to those infected prey in different ways (Fig. 3). For instance, parasitoids preferred healthy prey, while non-parasitoid, or strict, predators did not exhibit a preference for or against healthy prey. Thus, the type of predator affected whether or not IGP occurs in a community. The type of IGP dynamics, in turn, will have important consequences for whether the predators increase or decrease pathogen spread in the community (Rohr et al. 2015) and may have both short and long-term consequences for community dynamics.

Strict predators passively interact with pathogens through IGP (Fig. 1). In fact, pathogens can cause prey to be more readily captured, thus increasing the likelihood of a community exhibiting IGP dynamics (Thomas et al. 2006). This may often be the case if the energy gain from easier to capture prey outweighs the cost of nutrient loss due to suboptimal prey (Holmes and Bethel 1972). Predators may also consume pathogen-infected prey if they are unable to identify a prey item as infected. In terms of community dynamics, predators may remove pathogens from the environment (Roy et al. 1998); however, the predator may defecate viable pathogen (Beekman 1980, Biever et al. 1982, Bruck and Lewis 2002), thus increasing the number of infected resources (Cáceres et al. 2009). The importance of the nutritional value of infected prey, the energetic consequences of consuming infected prey, and increasing or decreasing pathogen availability in the community are important topics that require further investigation (Johnson et al. 2010) and are likely to vary among predators and pathogens.

Parasitoids may be either the $\mathrm{IG}_{\text {Pred }}$ or the $\mathrm{IG}_{\text {Prey }}$ (Hochberg et al. 1990, Thomas et al. 2006). They are the $\mathrm{IG}_{\text {Prey }}$ when pathogens kill a parasitized host before the parasitoid can complete development (Furlong and Pell 1996, Thomas et al. 2006), and are the $I_{\text {Pred }}$ if they finish development in the host, thus reducing the amount of host available or even killing the pathogen (Pell et al. 1997, Packer et al. 2003). However, as parasitoids avoid infected prey (Fig. 3), IGP interactions are likely rare in a parasitoid-pathogen-resource community. Instead, the community will simply consist of a predator and a pathogen competing for a shared resource and would not constitute an IGP community, though this may increase pathogen spread (Rohr et al. 2015).

Predator behavior is also important for shaping the interactions in a predator-pathogen IGP community. Rosenheim et al. (1995) showed that predators had varying levels of preference for parasitized larvae (i.e. lower preference: Brodeur and McNeil 1992, no preference: Hoelmer et al. 1994, higher preference: Ruberson et al. 1991). As suggested by Hochberg et al. (1990), consumers of pathogen-infected prey respond in a like manner (i.e. lower preference: Pell and Vandenberg 2002, no preference: Roy and Holt 2008, higher preference: Thomas et al. 2006). In general, we showed that parasitoids prefer healthy prey while strict predators, on average, do not prefer healthy or infected prey (Fig. 3). This result has important consequences for whether an IGP community can be maintained or if one or more members will be excluded (Vance-Chalcraft et al. 2007). Using IGP theory and experimental evidence to understand when a pathogen acting as a biocontrol agent is excluded through prey release rather than suppression will reduce wasted effort as those communities would collapse into simple predator-prey systems (Holt and Polis 1997, Vance-Chalcraft et al. 2007).

$\mathrm{IG}_{\text {Pred }}$ preference as well as $\mathrm{IG}_{\text {Prey }}$ behavior can also affect both short-term and long-term dynamics of a community. Rohr et al. (2015), using a trematode-amphibian system, showed that the $\mathrm{IG}_{\text {Pred }}$ of the host and the free-living parasite decrease infection rates in the host to a lesser extent than a predator that only consumes the parasite. The system's response to the $\mathrm{IG}_{\text {Pred }}$ is driven by changes in host density via density-mediated indirect effects and host behavior via trait-mediated indirect effects. This can have important consequences for IGP communities and the introduction of potential biocontrol agents in agricultural systems. For instance, using a predator that does not discriminate against infected prey would drive the pathogen locally extinct.

IGP theory also predicts that increased habitat complexity increases long-term stability (Janssen et al. 2007), and empirical studies support this prediction (Finke and Denno 2002, Okuyama 2008). Resources that become infected often change their movement behavior (Vasconcelos et al. 1996). As the pathogen spreads through a population, differential movement of infected and healthy individuals may set up a spatial mosaic such that certain parts of the landscape are dominated by either low or high quality prey items. This shifting mosaic may allow for long-term IGP stability on a larger spatial scale. Long-term studies investigating IGP stability in these communities will elucidate important consequences for disease dynamics.

Previous theoretical work on short-term dynamics showed that predators should readily consume parasiteinfected prey if the cost of a potential infection for the predator is low and catchability of the prey is high (Lafferty 1992). However, the model assumed that infected prey were trophically-transmitted and did not differ in quality. For our study, the parasites were concomitantly consumed and are lower quality as evidenced by changes in various life-history metrics, especially for strict predators. These metrics represent proxies for what may happen under field conditions; however, they are not direct measurements of a predator's response to the environment when presented with a landscape of non-infected and infected prey. For instance, we do not have enough information on differences in overall attack rate and handling time between infected and non-infected prey (but see Jiang et al. 2011). Our results point to the need to better understand how changes in foraging strategies in the field will affect both short-term and long-term dynamics from an empirical and theoretical perspective.

We focused our attention on communities made up of crop pests and their natural enemies. Given that these communities are simplified and potentially novel systems (Altieri and Letourneau 1982, Swift and Anderson 1994), they may not reflect the complexities of other ecological systems. However, to understand how intraguild predation influences more complex communities, it is necessary to start with communities where specific interactions can be directly observed and tested. These tractable systems also represent a sub-set of natural communities or community modules (Holt and 
Polis 1997), which are often the focus of research in nonagricultural systems. These communities isolate predators and pathogens and may yet hold more insights for future work.

Theory and empirical evidence suggest that resource quality affects long-term stability of an intraguild predation community. Given that resource quality affects both behavioral and life-history traits of consumers, resource quality can clearly decrease the fecundity and survival of the $\mathrm{IG}_{\text {Pred }}$ over a short time scale, such as that of an experiment. While the long-term effects are unknown, we can speculate that the short-term impacts arising from changes in resource quality will have important consequences for system stability. Longterm experiments are still needed to better understand the impacts of resource quality on IGP dynamics.

Acknowledgments - The authors would like to thank Jim Cronin for his support and comments. The authors would also like to thank Forrest P. Dillemuth, Matthew Faldyn, and Ben Van Allen for their invaluable assistance in preparation of this manuscript.

Funding - Finally, we would like to thank Louisiana State University for providing funding. BDE was supported by NSF-DEB1316334.

\section{References}

Altieri, M. A. and Letourneau, D. K. 1982. Vegetation management and biological control in agroecosystems. - Crop Protection 1: 405-430.

Bazykin, A. et al. 1981. The influence of predator saturation effect and competition among predators on predator-prey system dynamics. - Ecol. Model. 14: 39-57.

Beekman, A. G. 1980. The infectivity of polyhedra of nuclear polyhedrosis virus (N.P.V.) after passage through gut of an insect predator. - Experientia 36: 838-839.

Biever, K. D. et al. 1982. Use of a predator, Podisus maculiventris, (Hemiptera, Pentatmoidae) to distribute virus and initiate epizootics. - J. Econ. Entomol. 75: 150-152.

Borer, E. T. et al. 2007. Predators, parasitoids and pathogens: a cross-cutting examination of intraguild predation theory. - Ecology 88: 2681-2688.

Brodeur, J. and McNeil, J. N. 1992. Host behaviour modification by the endoparasitoid Aphidius nigripes: a strategy to reduce hyperparasitism. - Ecol. Entomol. 17: 97-104.

Browne, D. R. and Rasmussen, J. B. 2013. Rapid response of brook trout to removal of its intraguild prey, yellow perch. - Environ. Biol. Fish. 96: 915-926.

Bruck, D. J. and Lewis, L. C. 2002. Carpophilus freemani (Coleoptera: Nitidulidae) as a vector of Beawveria bassiana. - J. Invertebrate Path. 80: 188-190.

Cáceres, C. E. et al. 2009. Predator-spreaders: predation can enhance parasite success in a planktonic host-parasite system. - Ecology. 90: 2850-2858.

Clark, M. S. et al. 1994. Generalist predator consumption of armyworm (Lepidoptera: Noctuidae) and effect of predator removal on damage in no-till corn. - Environ. Entomol. 23: 617-622.

Cohen, J. 1992. Statistical power analysis. - Curr. Directions Psychol. Sci. 1: 98-101.

Creel, S. and Creel, N. M. 1996. Limitation of African wild dogs by competition with larger carnivores. - Conserv. Biol. 10: 526-538.

Duval, S. and Tweedie, R. 2000. Trim and fill: a simple funnelplot-based method of testing and adjusting for publication bias in meta-analysis. - Biometrics 56: 455-463.
Finke, D. L. and Denno, R. F. 2002. Intraguild predation diminished in complex-structured vegetation: implications for prey suppression. - Ecology 83: 643-652.

Flick, A. J. et al. 2016. Data from: The negative effects of pathogeninfected prey on predators: a meta-analysis. - Dryad Digital Repository, <http://dx.doi.org/10.5061/dryad.9ht4g >.

Furihata, S. et al. 2015. Bacteria endosymbiont, Wolbachia, promotes parasitism of parasitoid wasp Asobara japonica. - PloS ONE 10(10): e0140914.

Furlong, M. J. and Pell, J. K. 1996. Interactions between the fungal entomopathogen Zoophthora radicans Brefeld (Entomophthorales) and two hymenopteran parasitoids attacking the diamondback moth, Plutella xylostella L. - J. Invertebrate Pathol. 68: 15-21.

Gaskin, C. J. and Happell, B. 2013. Power of mental health nursing research: a statistical analysis of studies in the International Journal of Mental Health Nursing. - Int. J. Mental Health 22: 69-75.

Griffiths, K. and Holling, C. 1969. A competition submodel for parasites and predators. - Can. Entomol. 101: 785-818.

Gurevitch, J. and Hedges, L. V. 1993. Meta-analysis: combining the results of independent studies in experimental ecology. - In: Scheiner, S. and Gurevitch, J. (eds), The design and analysis of ecological experiments. Chapman and Hall, pp. 378-398.

Hochberg, M. et al. 1990. The dynamics of host-parasitoidpathogen interactions. - Am. Nat. 135: 74-94.

Hoelmer, K. et al. 1994. Interactions of the whitefly predator Delphastus pusillus (Coleoptera: Coccinellidae) with parasitized sweetpotato whitefly (Homoptera: Aleyrodidae). - Environ. Entomol. 23: 136-139.

Holmes, J. C. and Bethel, W. M. 1972. Modification of intermediate host behaviour by parasites. - Behav. Aspects Parasite Transmission 51: 123-149.

Holt, R. D. and Polis, G. A. 1997. A theoretical framework for intraguild predation. - Am. Nat. 145: 745-764.

Janssen, A. et al. 2007. Habitat structure affects intraguild predation. - Ecology 88: 2713-2719.

Jiang, J. et al. 2011. Combined effect of nuclear polyhedrosis virus and Microplitis pallidipes for the control of the beet armyworm, Spodoptera exigua. - Pest Manage. Sci. 67: 705-713.

Johnson, P. T. et al. 2010. When parasites become prey: ecological and epidemiological significance of eating parasites. - Trends Ecol. Evol. 25: 362-371.

King, A. B. and Saunders, J. L. 1984. The invertebrate pests of annual food crops in Central America: a guide to their recognition and control. - Overseas Development Administration.

Kohler, S. L. and Hoiland, W. K. 2001. Population regulation in an aquatic insect: the role of disease. - Ecology 82: 2294-2305.

Lafferty, K. D. 1992. Foraging on prey that are modified by parasites. - Am. Nat. 140: 854-867.

Lafferty, K. D. et al. 2008. Parasites in food webs: the ultimate missing links. - Ecol. Lett. 11: 533-546.

Liu, X. et al. 2014. Natural enemies delay insect resistance to Bt crops. - PLoS ONE 9(3): e90366.

Mooney, K. A. et al. 2010. Interactions among predators and the cascading effects of vertebrate insectivores on arthropod communities and plants. - Proc. Natl Acad. Sci. USA 107: 7335-7340.

Moscardi, F. 1999. Assessment of the application of baculoviruses for control of Lepidoptera. - Annu. Rev. Entomol. 44: 257-289.

Okuyama, T. 2008. Intraguild predation with spatially structured interactions. - Basic Appl. Ecol. 9: 135-144.

Packer, C. et al. 2003. Keeping the herds healthy and alert: implications of predator control for infectious disease. - Ecol. Lett. 6: 797-802. 
Paine, R. T. 1980. Food webs: linkage, interaction strength and community infrastructure. - J. Anim. Ecol. 49: 667-685.

Pell, J. and Vandenberg, J. 2002. Interactions among the aphid Diuraphis noxia, the entomopathogenic fungus Paecilomyces fumosoroseus and the Coccinellid Hippodamia convergens. - Biocontrol Sci. Technol. 12: 217-224.

Pell, J. et al. 1997. Interactions between two aphid natural enemies, the entomopathogenic fungus Erynia neoaphidis Remaudière and Hennebert (Zygomycetes: Entomophthorales) and the predatory beetle Coccinella septempunctata L.(Coleoptera: Coccinellidae). - J. Invertebrate Pathol. 69: 261-268.

Poland, T. M. et al. 2007. Twenty million ash trees later: current status of emerald ash borer in Michigan. - Newslett. Mich. Entomol. Soc. 52: 10-14.

Power, M. E. et al. 1985. Grazing minnows, piscivorous bass, and stream algae: dynamics of a strong interaction. - Ecology 66: $1448-1456$.

Rohr, J. R. et al. 2015. Predator diversity, intraguild predation, and indirect effects drive parasite transmission. - Proc. Natl Acad. Sci. USA 112: 3008-3013.

Roitberg, B. et al. 2001. Fitness, parasitoids, and biological control: an opinion. - Can. Entomol. 133: 429-438.

Rosenberg, M. S. et al. 2000. MetaWin: statistical software for meta-analysis. - Sinauer.

Rosenheim, J. A. et al. 1993. Influence of intraguild predation among generalist insect predators on the suppression of an herbivore population. - Oecologia 96: 439-449.

Rosenheim, J. A. et al. 1995. Intraguild predation among biological-control agents: theory and evidence. - Biol. Control 5: 303-335.

Roy, M. and Holt, R. D. 2008. Effects of predation on hostpathogen dynamics in SIR models. - Theor. Popul. Biol. 73: 319-331.

Supplementary material (available online as Appendix oik03458 at <www.oikosjournal.org/appendix/oik-03458>). Appendix 1.
Roy, H. et al. 1998. Implications of predator foraging on aphid pathogen dynamics. - J. Invertebrate Pathol. 71: 236-247.

Ruberson, J. R. et al. 1991. Suitability of prey infected by nuclear polyhedrosis virus for development, survival, and reproduction of the predator Nabis roseipennis (Heteroptera: Nabidae). - Environ. Entomol. 20: 1475-1479.

Schmitz, O. J. and Suttle, K. B. 2001. Effects of top predator species on direct and indirect interactions in a food web. - Ecology 82: 2072-2081.

Sieber, M. and Hilker, F. M. 2011. Prey, predators, parasites: intraguild predation or simpler community modules in disguise? - J. Anim. Ecol. 80: 414-421.

Stiling, P. and Cornelissen, T. 2005. What makes a successful biocontrol agent? A meta-analysis of biological control agent performance. - Biol. Control 34: 236-246.

Swift, M. and Anderson, J. 1994. Biodiversity and ecosystem function in agricultural systems. - In: Biodiversity and ecosystem function. Springer, pp. 15-41.

Thieltges, D. W. et al. 2013. Parasites as prey in aquatic food webs: implications for predator infection and parasite transmission. - Oikos 122: 1473-1482.

Thomas, M. B. et al. 2006. Trophic and guild interactions and the influence of multiple species on disease. - In: Trophic and guild in biological interactions control. Springer, pp. 101-122.

Vance-Chalcraft, H. D. et al. 2007. The influence of intraguild predation on prey suppression and prey release: a meta-analysis. - Ecology 88: 2689-2696.

Vasconcelos, S. D. et al. 1996. Modified behavior in baculovirusinfected lepidopteran larvae and its impact on the spatial distribution of inoculum. - Biol. Control. 7: 299-306.

Williams, T. et al. 2013. Biological pest control in Mexico. - Annu. Rev. Entomol. 58: 119-140.

Xie, J. et al. 2014. Male killing Spiroplasma protects Drosophila melanogaster against two parasitoid wasps. - Heredity 112: 399-408. 